\title{
Effect of Microwave and Conventional Modes of Heating on Sintering Behavior, Microstructural Evolution and Mechanical Properties of Al-Cu-Mn Alloys
}

\author{
A. Muthuchamy ${ }^{1}$, Muthe Srikanth ${ }^{2}$ (D), Dinesh K. Agrawal ${ }^{3, *}$ and A. Raja Annamalai ${ }^{2, *(D)}$ \\ 1 Department of Metallurgical and Materials Engineering, NIT, Tiruchirapalli 620015, Tamil Nadu, India; \\ muthuchamy@nitt.edu \\ 2 Centre for Innovative Manufacturing Research, VIT, Vellore 632014, Tamil Nadu, India; \\ muthe.srikanth@vit.ac.in \\ 3 Materials Research Institute, The Pennsylvania State University, State College, PA 16802, USA \\ * Correspondence: dxa4@psu.edu (D.K.A.); raja.annamalai@vit.ac.in (A.R.A.)
}

check for

updates

Citation: Muthuchamy, A.; Srikanth, M.; Agrawal, D.K.; Annamalai, A.R. Effect of Microwave and

Conventional Modes of Heating on Sintering Behavior, Microstructural Evolution and Mechanical Properties of Al-Cu-Mn Alloys. Molecules 2021, 26, 3675. https://doi.org/10.3390/ molecules26123675

Academic Editor: Satoshi Horikoshi

Received: 19 May 2021

Accepted: 8 June 2021

Published: 16 June 2021

Publisher's Note: MDPI stays neutral with regard to jurisdictional claims in published maps and institutional affiliations.

Copyright: (c) 2021 by the authors. Licensee MDPI, Basel, Switzerland. This article is an open access article distributed under the terms and conditions of the Creative Commons Attribution (CC BY) license (https:/ / creativecommons.org/licenses/by/ $4.0 /)$.

\begin{abstract}
In this research, we intended to examine the effect of heating mode on the densification, microstructure, mechanical properties, and corrosion resistance of sintered aluminum alloys. The compacts were sintered in conventional (radiation-heated) and microwave $(2.45 \mathrm{GHz}$, multimode) sintering furnaces followed by aging. Detailed analysis of the final sintered aluminum alloys was done using optical and scanning electron microscopes. The observations revealed that the microwave sintered sample has a relatively finer microstructure compared to its conventionally sintered counterparts. The experimental results also show that microwave sintered alloy has the best mechanical properties over conventionally sintered compacts. Similarly, the microwave sintered samples showed better corrosion resistance than conventionally sintered ones.
\end{abstract}

Keywords: aluminum alloys; conventional sintering; microwave sintering; mechanical properties; corrosion resistance

\section{Introduction}

A wide range of applications is provided and its alloys, with a unique combined advantage which makes it the material to choose for many applications such as aerospace, the automotive, military, etc. due to their low density, coefficient of thermal expansion, high strength, wear-resistance, and improved damping properties [1,2]. Aluminum-metal matrix composites have received comprehensive attention for functional and fundamental reasons among the materials of tribological significance. Due to theirhigh compressibility, less density, specific strength, and economical processing, aluminum alloy composites can be quickly produced by the powder metallurgy technique compared with the other available fabrication techniques [3]. Aluminum alloys and aluminum-based metal matrix composites have found applications in the manufacture of various automotive engine components. The metal matrix composites' main advantage is mechanical properties such as hardness and yield strength to be adequately regulated by strengthening the matrix and substantial mass control, which is necessary, mainly when used mutually [4]. Aluminum metal matrix composites are also used in the transportation sector due to their lower density, lower airborne emission, and less noise, which helps maintain the environmental regulations and provides good fuel economy [5]. The high strength to weight ratio of Aluminum matrix composites has also successfully cemented their place in military applications. The Young's modulus of pure Aluminum can be enhanced by $300 \%$ (70 GPa to $240 \mathrm{GPa}$ ) by reinforcing the aluminum fibers [5]. Aluminum-based powder metallurgy alloys were used to produce near-net-shape products with high material utilization with less cost, lower processing temperature, and refined homogeneous microstructure with a lesser amount of porosity [6,7]. 
Further research into powered metal's ability to absorb and dissipate microwave radiation has opened new powder metallurgy opportunities. Microwave sintering is an efficient, economic, and valuable approach to processing some P/M materials [8]. Microwave sintering has advantages like enhanced diffusion processes, reduced energy consumption, and rapid heating rates. Microwave sintering considerably reduces processing times, decreases sintering temperatures, improves physical and mechanical properties, and has lower environmental hazards. These are some features that have not been observed in conventional sintering $[9,10]$.

Much research has been carried out for aluminum metal powder mixed with varied compositions of the alloying elements. Aluminum-manganese alloys and aluminumcoppers are two of the most-used combinations. Al-Mn alloys have elevated formability and corrosion resistance with high heat transfer coefficients, making them feasible for radiators, packaging, and roofing applications [11]. Such alloys have a very high strength-toweight ratio and a density slightly higher than that of various plastics. Inter metallic-phase formation of Al-Mn elements by the adsorption of Mn within the liquid phase of Al acts as the driving force for solidification [12,13]. Al-Cu alloys are heat-treatable, and hence they possess high strength, especially at high homologous temperatures $\left(200-300{ }^{\circ} \mathrm{C}\right)$, with higher toughness, resulting in a wide range of aircraft and transportation industry applications [14]. The compact density shows improvement after sintering due to precipitation due to the copper swaging nature of copper $[15,16]$.

The present research attempts to study the effect of heating mode on the physical and mechanical properties of aluminum alloy composites produced through the powder metallurgy route. The effects of copper and manganese addition on the sinterability of the same were also studied.

\section{Materials and Methods}

For the present investigation, gas atomized pure elemental form aluminum, copper, and manganese powders were purchased from Krish Met Tech Pvt. Ltd.(Annamalai Colony St, Annamalai Colony, Virugambakkam, Chennai, Tamil Nadu, India) Chennai. By varying the $\mathrm{Al}, \mathrm{Cu}$, and Mn contents, three distinct alloys are designed, as shown in Table 1 . The characteristics of the as-received powders are listed in Table 2. According to the designed composition, elemental powders are separately blended using a mortar for 60 min to obtaina uniform composition.

Table 1. Powder Compositions concerning wt $\%$ used in the present study.

\begin{tabular}{cccc}
\hline Sample No. & Aluminum Wt $\boldsymbol{~}^{*}$ & Copper $\mathbf{W t} \mathbf{*}^{*}$ & Manganese $\mathbf{W t} \boldsymbol{*}^{*}$ \\
\hline 1 & 77.5 & 0 & 22.5 \\
\hline 2 & 57.28 & 18.6 & 24.12 \\
\hline 3 & 65 & 20 & 15 \\
\hline
\end{tabular}

* Supplier: Krish Met Tech PVT. LTD, Chennai, India.

Table 2. Cumulative powder size of Aluminum.

\begin{tabular}{cc}
\hline Cumulative Powder Size & $\mu \mathrm{m}$ \\
\hline D10 & 12.6 \\
\hline D50 & 31.0 \\
\hline D90 & 44.2 \\
\hline
\end{tabular}

The powders were subjected to uniaxial compaction at $400 \mathrm{MPa}$ and were made as cylindrical pellets ( $25 \mathrm{~mm}$ diameter) using a Universal Testing Machine (model: Instron 8801, Norwood, MA, USA). Zinc stearate was used as a die wall lubricant [13]. All compacted alloys are sintered at $550{ }^{\circ} \mathrm{C}$ for $60 \mathrm{~min}$ using (i) conventional sintering in a tubular furnace (model: VBCC, TUBULAR FURNACE, Chennai, Tamilnadu, India) at a 
heating rate of $5{ }^{\circ} \mathrm{C} / \mathrm{min}$, and (ii) microwave sintering furnace (model: VBCC HYTERM FURNACE Chennai, Tamilnadu, India, multimode cavity $2.45 \mathrm{GHz}, 6 \mathrm{~kW}$ ) at a heating rate of $30^{\circ} \mathrm{C} / \mathrm{min}$. Alumina boats were used for placing the samples inside the furnaces. Age-hardening of sintered samples was performed at $150{ }^{\circ} \mathrm{C}$ for $60 \mathrm{~min}$ in a box furnace (model: R257 INDFURN SUPERHEAT FURNACES, Chennai, Tamil Nadu, India)at a heating rate of $5{ }^{\circ} \mathrm{C} / \mathrm{min}$, and was water quenched to room temperature. By calculating the volume and weight of the pellets, the sintered densities of the pellets were determined. The densification parameter of the samples was calculated as:

$$
\begin{gathered}
\text { Densification parameter }=\frac{\text { Sintered density }- \text { Green density }}{\text { Theoritical density }- \text { Green density }} \\
\text { Radial Shrinkage }=\frac{\text { Green diameter }- \text { Sintered diameter }}{\text { Green diameter }} \\
\text { Axial Shrinkage }=\frac{\text { Green height }- \text { Sintered height }}{\text { Green height }}
\end{gathered}
$$

The sintered samples were initially polished with 220, 400, 800, 1000, 1200, 1500, 1800, and 2000 grit SiCemery papers, progressively, and mirror polishing was done on the disc polishing machine with diluted alumina solutions on a velvet cloth. After polishing, the samples were etched using Keller's reagent $\left(3 \mathrm{~mL}-\mathrm{HNO}_{3}, 2 \mathrm{~mL}-\mathrm{HCl}, 1 \mathrm{~mL}-\mathrm{HF}\right.$, and $100 \mathrm{~mL}$ $\mathrm{H}_{2} \mathrm{O}$ ) [17]. The polished sample microstructures were evaluated with optical microscopy (model: ZEISS-AXIO vert A1, Jena, Germany). Microhardness of all the compositions was tested using the Vickers hardness testing machine (model: MMT-X7B, no: MM5562X, Matsuzawa Co.,Ltd, Akita, Japan)with a load of $0.5 \mathrm{kgf}$, with $10 \mathrm{~s}$ dwell time. The indent's diagonal lengths were measured, and the experiment was repeated three times to obtain a precise value.

The Vickers hardness of the sintered alloys is found out using the following equation:

$$
\mathrm{Hv}=\frac{1.854 \times \mathrm{P}}{\mathrm{a}^{2}}
$$

where $\mathrm{p}=$ Load applied, $\mathrm{a}=$ Average length of the diagonal $=\frac{\mathrm{d}_{1}+\mathrm{d}_{2}}{2}, \mathrm{~d}_{1}=$ length of diagonal 1 , $\mathrm{d}_{2}=$ length of diagonal 2 .

A scanning electron microscope [model: ZEISS-EVO18, Jena, Germany] was used in backscattered electron imaging mode for microstructural examination. The sample's electrochemical activity was tested using the electrochemical method in a freely aerated $0.1 \mathrm{~N} \mathrm{HCl}$ solution. Before polarization, the polished samples were allowed to stabilize for $1 \mathrm{~h}$ to obtain stable open circuit potential (OCP). Electrochemical tests were carried out in a flat corrosion cell using a standard three-electrode configuration of the sample as the working electrode, platinum mesh as the counter electrode, and $\mathrm{Ag} / \mathrm{AgCl}$ reference electrodes. Potentiodynamic polarization tests were carried out from $-250 \mathrm{mV}$ versus $\mathrm{OCP}$ to $+1600 \mathrm{mV}$ versus the reference electrode at a CT scan rate of $0.1667 \mathrm{mV}$. From the corresponding anodic and cathodic curves, the Tafel curves were created. The corrosion potential $\left(\mathrm{E}_{\mathrm{corr}}\right)$, corrosion current $\left(\mathrm{I}_{\mathrm{corr}}\right)$, and corrosion rate were determined from the polarization curves. The corrosion rate was determined by using the 1st-Stern method [18] and is expressed as follows:

$$
\text { Corrosion rate }\left(\frac{\mathrm{mm}}{\text { year }}\right)=0.0033 \times \frac{\mathrm{e}}{\rho} \times \mathrm{I}_{\text {corr }}
$$

where e is the equivalent weight $(\mathrm{g}), \rho$ is the density within the material $\left(\mathrm{mg} / \mathrm{m}^{3}\right)$, and $\mathrm{I}_{\text {corr }}$ is the corrosion current $\left(\mathrm{mA} / \mathrm{m}^{2}\right)$. 


\section{Results \& Discussion}

\subsection{Densification Response}

The heating profiles of the compacts were as shown in Figure 1. The overall heating rate obtained in the microwave furnace was $30^{\circ} \mathrm{C} / \mathrm{min}$ at $550{ }^{\circ} \mathrm{C}$ for $60 \mathrm{~min}$. concerning the heating cycle; a $34 \%$ reduction in the processing time was obtained during microwave sintering against the slower heating rate $\left(5^{\circ} \mathrm{C} / \mathrm{min}\right)$ of a conventional furnace. A similar trend was depicted in the observations of $\mathrm{C}$. Padmavathi et al. [16]. Table 3 shows the relative sintered density of the microwave and conventional sintered alloys. The microwave sintering technique yields better density as compared to a conventional sintering method. The presence of Aluminum enhances the density within the material. In contrast, Ananda Kumar et al. [4] validated that \% porosity increased with a decrease in $\mathrm{Al}$ content for aluminum in the composites. After compaction, on heating the green compact just above the solidus temperature and high compressibility of aluminum, the particle starts to fuse, and hence densification takes place employing solid-phase sintering, which C. Padmavathi et al. explain [19]. During subsequent heating, semi-solid phases are formed at corresponding eutectic temperatures depending on the alloy composition. Higher sintering temperatures lead to the formation of a higher amount of the semi-solid phases, and hence further densification is possible, and the sample can be compressed to a greater extent. Similar behavior was observed for various aluminum powder compositions sintered at $550{ }^{\circ} \mathrm{C}$ to a higher sintered density ( $81.54 \%$ theoretical). Based on the weight percentage of aluminum in the composition, the rate of disintegration of particulate reinforcements followed by diffusion bonding and grain coarsening varies. The Al-57.28, $\mathrm{Cu}-18.6$, and $\mathrm{Mn}$ 24.12 compositions have the lowest sinter-density among all the other compositions. The percentage of copper was directly proportional to the number of precipitates in the grains. A higher amount of densification was noted with the increase in copper content in both the sintered samples. At the time of aging, a further increase in precipitation was observed. The increase in the densification parameter was explained by DesalegnWogasoWolla et al. [15]. Weight and top layer loss in microwave sintering are comparatively less, as the heating was performed radially, outwards, within the sample. Since heat concentration was greater at the core, the sample's surface was safe throughout the entire process, similar to what was explained by Morteza Oghbaei et al. [9].

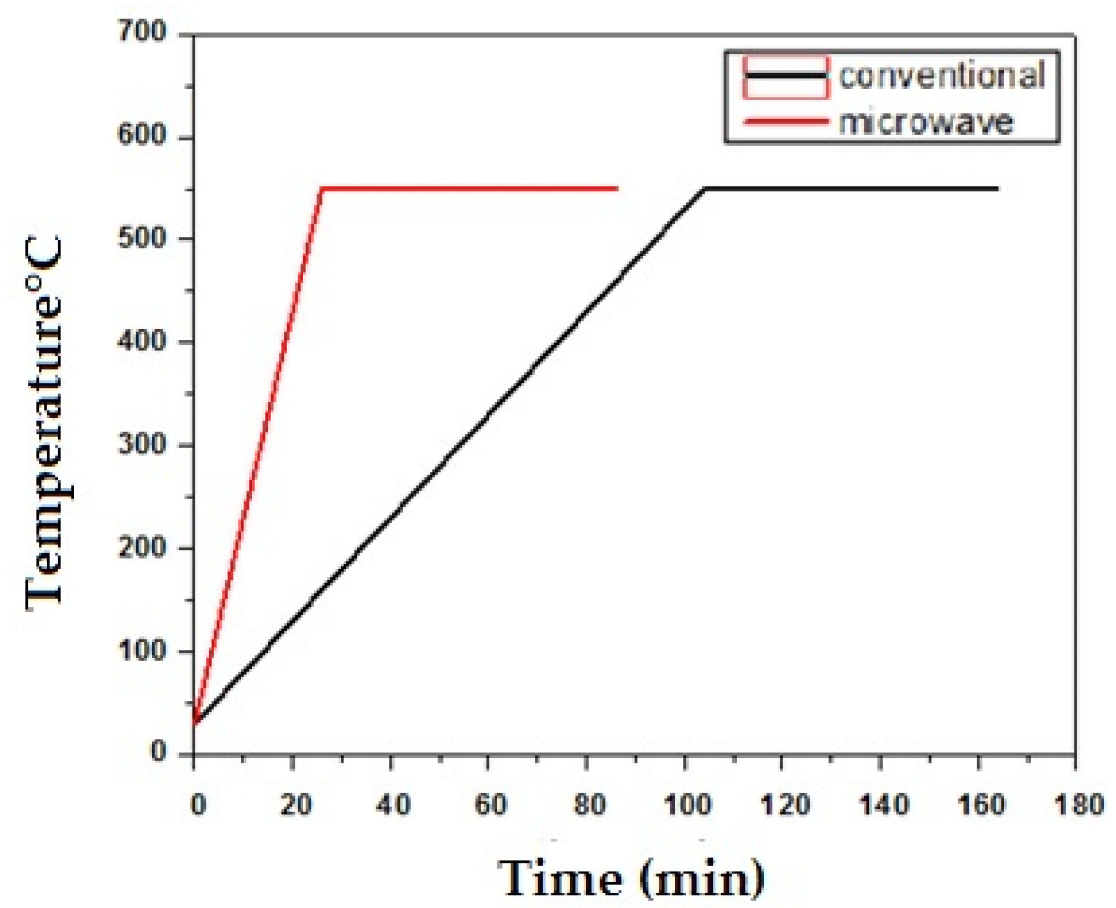

Figure 1. Heating profile of conventional sintering and microwave sintering. 
Table 3. Effect of compaction pressure and sintering on the densification response of Al-alloys compacted at $400 \mathrm{MPa}$ and sintered at $550{ }^{\circ} \mathrm{C}$.

\begin{tabular}{|c|c|c|c|c|c|c|c|}
\hline Composition & Sintering Mode & $\begin{array}{l}\text { Radial } \\
\text { Shrinkage }\end{array}$ & Axial Shrinkage & $\%$ wt Loss & $\begin{array}{l}\text { Green Density } \\
\text { (\% Theoretical) }\end{array}$ & $\begin{array}{l}\text { Sinter Density } \\
\text { (\% Theoretical) }\end{array}$ & $\begin{array}{c}\text { Densification } \\
\text { Parameter }\end{array}$ \\
\hline \multirow{2}{*}{ 77.5Al-22.5Mn } & Conventional & 0.001 & 0.533 & 0.072 & 78.8 & 80.77 & 0.029 \\
\hline & Microwave & 0.059 & 2.967 & 0.297 & 80.19 & 81.54 & 0.125 \\
\hline \multirow{2}{*}{$\begin{array}{l}57.28 \mathrm{Al}-18.6 \mathrm{Cu}- \\
24.12 \mathrm{Mn}\end{array}$} & Conventional & 0.039 & 0.125 & 0.34 & 71.12 & 71.51 & 0.013 \\
\hline & Microwave & 0.078 & 0.152 & 3.721 & 70.4 & 73.30 & 0.096 \\
\hline \multirow{2}{*}{$65 \mathrm{Al}-20 \mathrm{Cu}-15 \mathrm{Mn}$} & Conventional & 0.023 & 0.035 & 0.097 & 71.94 & 72.06 & 0.004 \\
\hline & Microwave & 0.551 & 4.189 & 0.194 & 71.4 & 75.40 & 0.138 \\
\hline
\end{tabular}

\subsection{Micro-Hardness}

The variations in micro-hardness of samples, with varying $\mathrm{Cu}$ and $\mathrm{Mn}$ weight contents, sintered through conventional and microwave techniques are shown in Table 4. It was found that the addition of copper particulates could effectively enhance the micro-hardness as the elemental hardness of copper $(369 \mathrm{HV})$ is higher than the other elements within the composition, and also because of the formation of precipitates due to aging, as described by J. Sun et al. [18]. In addition to this, Rainforth et al. [20] have also observed that the alloy A2124 (91.2Al-3.8Cu) exhibits more work hardening, while A3004 exhibited minimal work hardening. Beyond a specific percentage composition of copper, a decrease in hardness was observed due to a reduction in grain growth, limiting the semi-solid state's flow within the aluminum grain boundaries. The results indicated that using the microwave sintering technique process had an overall advantage compared with the conventional sintering method considering the improvement in hardness, as reported by Morteza Oghbaei et al. [9]. From the SEM and optical microstructure of the $\mathrm{Cu}$ added alloys observed, copper is distributed equally in microwave sintered alloy. Still, in the conventional sintered alloys, copper is concentrated in some regions, and copper is not distributed uniformly throughout the alloy due to the high time given to the alloy during sintering. Even distribution of the $\mathrm{Cu}$ help to form a uniform distribution of precipitates, and these precipitates are influencing an increase in the hardness of the microwave sintered alloys.

Table 4. Effect of heating mode on Vickers hardness of Al alloy compacts at a $50 \mathrm{gm}$ load for $10 \mathrm{~s}$ dwell time.

\begin{tabular}{ccc}
\hline Composition & Conventional & Microwave \\
\hline $77.5 \mathrm{Al}-22.5 \mathrm{Mn}$ & $52.67 \pm 5 \mathrm{Hv}$ & $86.65 \pm 5 \mathrm{Hv}$ \\
\hline $57.28 \mathrm{Al}-18.6 \mathrm{Cu}-24.12 \mathrm{Mn}$ & $94.46 \pm 10 \mathrm{Hv}$ & $745.8 \pm 10 \mathrm{Hv}$ \\
\hline $65 \mathrm{Al}-20 \mathrm{Cu}-15 \mathrm{Mn}$ & $114.03 \pm 5 \mathrm{Hv}$ & $580.37 \pm 10 \mathrm{Hv}$ \\
\hline
\end{tabular}

\subsection{Microstructural Results}

The optical microstructures of conventionally and microwave sintered samples after polishing and etching are shown in Figure 2a-c. The microstructure revealed uniform distribution of $\mathrm{Cu}$ and $\mathrm{Mn}$ in the $\mathrm{Al}$ matrix. However, at some sites, clusters of $\mathrm{Al}-\mathrm{Cu}$ phases were observed at the surface along with porosity. At $550{ }^{\circ} \mathrm{C}$, aluminum melted and was distributed throughout the compact. This resulted in the formation of intermetallic phases along the grain boundaries. Dispersed Mn phases were found to be homogeneously distributed in all the samples of Al matrix made through the conventional sintering method, and the phenomenon is validated by Alexandra V. Khvan et al. [13]. The microwave processed sample possessed fewer amounts of pores, which are very small and uniformly distributed, while the conventionally sintered samples are found to have more porosity except in the case of $\mathrm{Al}-20 \% \mathrm{Cu}-15 \% \mathrm{Mn}$ (Figure 2c). The addition of $\mathrm{Cu}$ in Al-Mn alloy resulted in the formation of intermediate granules of $\mathrm{Cu}$ during the conventional mode of sintering, but it was found to be homogeneously dispersed between $\mathrm{Al}$ and $\mathrm{Mn}$ in 
the microwave due to lesser precipitation time, which was also observed by Morsi M. Mahmoud et al. [21]. Large intermediate granules were only formed during conventional sintering except in the case of $\mathrm{Al}-18.6 \% \mathrm{Cu}-24.12 \% \mathrm{Mn}$ composition. It was also found that the size of the $\mathrm{Cu}$ granules reduced in $\mathrm{Al}-20 \% \mathrm{Cu}-15 \% \mathrm{Mn}$, as shown in Figure 2c. The availability of pure aluminum phases was lowest in the microwave sintered compact of $\mathrm{Al}-18.6 \% \mathrm{Cu}-24.12 \% \mathrm{Mn}$ composition, shown as the result of EDS (Table 5).
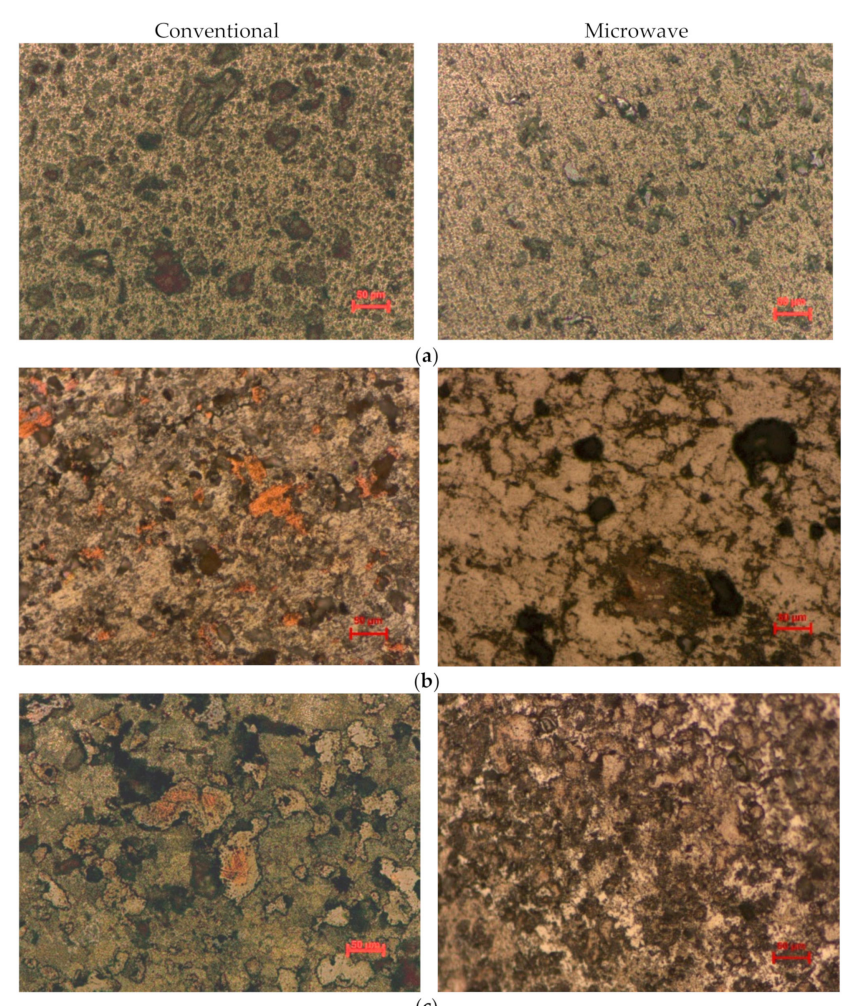

Figure 2. Optical microstructure of etched aluminum compacts of (a) Al-22.5\%Mn; (b) Al$18.6 \% \mathrm{Cu}-24.12 \% \mathrm{Mn}$; (c) $\mathrm{Al}-20 \% \mathrm{Cu}-15 \% \mathrm{Mn}$ sintered in conventional furnace (left) and microwave furnace (right).

Table 5. Weight percentages of elements resulted from EDS analysis of particulate compacts of Al-alloys sintered in conventional and microwave furnaces.

\begin{tabular}{ccccccc}
\hline \multirow{2}{*}{ Sample } & \multicolumn{2}{c}{ Al-22.5\%Mn } & \multicolumn{2}{c}{ Al-18.6\%Cu-24.12\%Mn } & \multicolumn{2}{c}{ Al-20\%Cu-15\%Mn } \\
\cline { 2 - 7 } & Conventional & Microwave & Conventional & Microwave & Conventional & Microwave \\
\hline Al wt \% & 97.65 & 98.16 & 81.98 & 54.70 & 39.52 & 60.57 \\
\hline Cu wt \% & 0 & 0 & 1.79 & 22.73 & 13.99 & 20.78 \\
\hline Mn wt $\%$ & 2.35 & 1.84 & 16.22 & 22.56 & 46.48 & 18.63 \\
\hline
\end{tabular}

\subsection{Scanning Electron Microscopy}

Figure 3a-c shows the representative SEM micrograph of the sintered compacts in conventional and microwave mode. The micrograph shows that $\mathrm{Mn}$ and $\mathrm{Cu}$ particle sizes were small with microwave sintering as compared to conventional sintering. The SEM images in Figure 3a, representing Al-22.5\%Mn composite, clearly revealed a uniform distribution of Mn particles within $\mathrm{Al}^{\prime} \mathrm{s}$ matrix in the case of microwave sintering, and it was similar to that reported by Morteza Oghbaei et al. [9]. Table 5 shows the EDS spectrum, which depicts $\mathrm{Al}, \mathrm{Cu}$, and Mn's peaks and their respective elemental percentage. In all the compositions, the percentage of pure Mn was relatively more minor, which would account for the formation of various intermetallics between $\mathrm{Al}$ and $\mathrm{Mn}$, as Alexandra V. Khvan 
et al. [13] described the solidification of Al-Mn intermetallics which led to the formation of $\mathrm{Al}_{11} \mathrm{Mn}_{4}$ and similar intermetallic phases, which was more likely during the consolidation process. Such intermetallic formation was observed profoundly in microwave sintering compared to conventional sintering and led to better physical and mechanical properties. M. Ellner et al. [22] described that $\mathrm{MnAl}_{0.8}$ showed a distinct behavior of brass-like ' $\mu$ phases,' which was stable and expected to have a greater degree of mechanical properties. For both composites which contain copper, the less pure copper percentage, as depicted in EDS, resulted in less precipitation of copper at the grain boundaries in the case of conventional sintering as compared to microwave. LuboKloc et al. [21] described in their studies on aluminum alloy the high formation of inter-metallic of Al-Cu, which results in less availability of pure metals to precipitate and hence disturbs the mechanical properties of the sample. Smaller and more uniformly distributed intermetallic granules were observed in microwave sintering compared to the conventional mode of sintering, validated by Morsi M. Mahmoud et al. [13]. Tinier pore size and uniform distribution, which were observed in the SEM of microwave sintered sample, enabled us to confirm the possibility of higher and unified mechanical and physical properties, as expressed by MortezaOghbaei et al. [9].
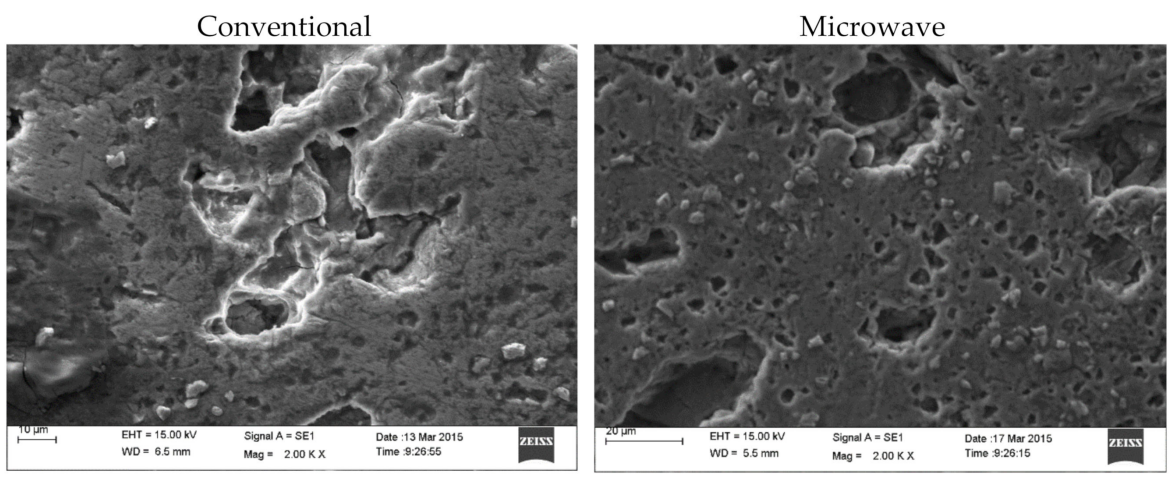

(a)
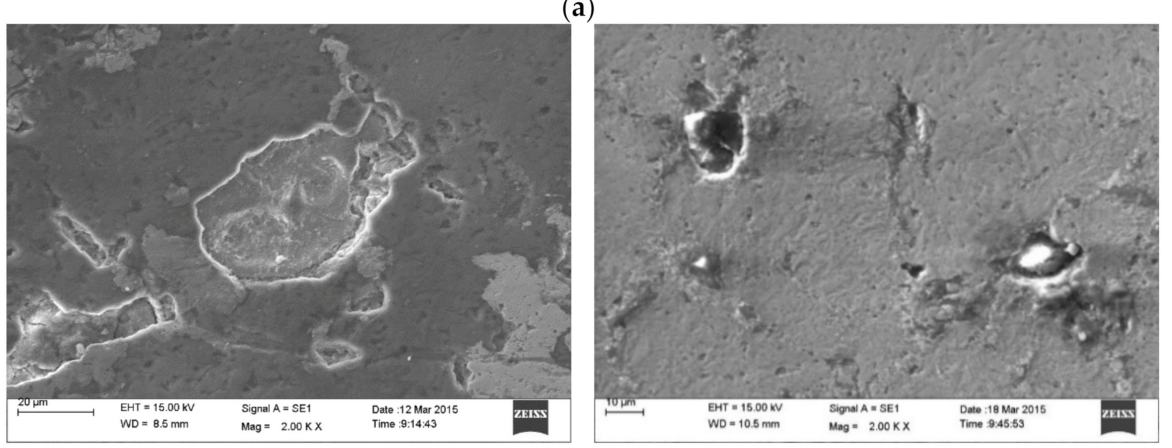

(b)
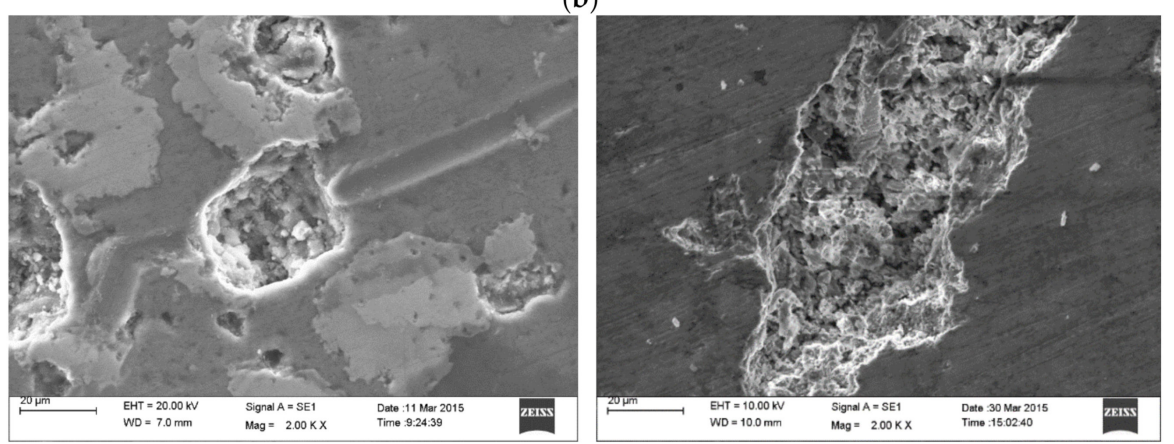

(c)

Figure 3. SEM microstructure of Aluminum compacts of (a) Al-22.5\%Mn; (b) Al-18.6\%Cu-24.12\%Mn; (c) $\mathrm{Al}-20 \% \mathrm{Cu}-15 \% \mathrm{Mn}$ sintered in conventional furnace (left) and microwave furnace (right). 


\subsection{Electrochemical Study}

Table 6 represents the corrosion characteristics of the Al-Cu-Mn alloys obtained through conventional and Microwave sintering. Figure $4 \mathrm{a}-\mathrm{c}$ represents the potential polarization curves of all the compositions sintered with conventional and microwave modes of sintering. As current density was inversely relative and directly proportional to the corrosion rate, it showed microwave sintering results yielded better corrosion resistance than conventional sintering in all study compositions. As the percentage porosity was reduced to microwave sintering, the corrosion rate was reduced due to the reduced anodic region on the sintered compact's surface layers. The compact sintered in the microwave furnace stabilized at lower potentials, compared to be compact sintered in conventional. For conventional sintering, a higher corrosion potential ( $\left.\mathrm{E}_{\text {corr }}\right)$, lower corrosion current density $\left(\mathrm{I}_{\text {corr }}\right)$, and lower corrosion rate were observed, and a similar result was obtained by C. Padmavathi et al. [16]. Al-18.6\%Cu- $24.12 \% \mathrm{Mn}$ composition showed a high corrosion rate when compared with remaining compositions. The result obtained from EDS analysis (Table 5) depicted that the availability of $\mathrm{Cu}$ and $\mathrm{Mn}$ in microwave sintering is more than conventional, indicating fewer chances of Al-Cu alloys Al-Mn alloy formation the grain boundaries, and it resulted in lesser corrosion rate. All liquid phase formation and alloy formation with $\mathrm{Cu}$ by adsorption phenomena led to a reduction of pure Al's share on the surface level and sub-surface level in the case of conventional sintering. The open-circuit potentials of $\mathrm{Al}-\mathrm{Cu}$ alloys, in solutions of near-neutral $\mathrm{pH}$, were greater than or equal to the $\mathrm{E}_{\mathrm{pit}}$ for pure $\mathrm{Al}$ over a broad range of $\mathrm{Cu}$ concentrations, as explained by Faith George et al. [23]. Deposition corrosion is a particular case of galvanic corrosion that takes the form of pitting. When particles of a more cathodic metal in the solution spread out on an aluminum surface to set up local galvanic cells, this confirms the widely held view that galvanic coupling of $\mathrm{Al}-\mathrm{Cu}$ intermetallic particles with the $\mathrm{Al}$ promotes pitting and deposition corrosion.

Table 6. Passivity parameters obtained for sintered compacts of $\mathrm{Al}$-alloys of $\mathrm{Cu}$ and $\mathrm{Mn}$ from the anodic polarization study in $0.1 \mathrm{~N} \mathrm{HCl}$. All the compositions were sintered at $550{ }^{\circ} \mathrm{C}$ in a conventional as well as microwave furnace.

\begin{tabular}{ccccc}
\hline \multirow{2}{*}{ Composition } & Sintering Mode & Icorr & Ecorr & \multicolumn{2}{c}{ Corrosion Rate } \\
\cline { 2 - 5 } & & $\mathbf{( m A / \mathbf { c m } ^ { 2 } )}$ & $\mathbf{( V )}$ & $\mathbf{( m p y )}$ \\
\hline \multirow{2}{*}{ 77.5Al-22.5Mn } & Conventional & 1.135 & 0.003 & 1.407 \\
\cline { 2 - 5 } & Microwave & 1.103 & -0.034 & 2.398 \\
\hline \multirow{2}{*}{ 57.28Al-18.6Cu-24.12Mn } & Conventional & 2.171 & 0.005 & 1.803 \\
\cline { 2 - 5 } & Microwave & 1.672 & -0.14 & 1.276 \\
\hline \multirow{2}{*}{ 65Al-20Cu-15Mn } & Conventional & 1.29 & 0.019 & 1.101 \\
\hline
\end{tabular}

Al-20\%Cu-20-15\%Mn composition shows higher corrosion resistance in all the compositions. Even Al-Mn alloy is less corrosive, but pure $\mathrm{Mn}$ has high corrosive resistance. Jutatip Namahoot et al. [24] expressed that low-volume fraction of intermetallic phases or high content of $\mathrm{Mn}$ in the matrix and the intermetallic phases can improve the corrosion resistance of Al-Mn alloys. This explains why $\mathrm{Al}-20 \% \mathrm{Cu}-20-15 \% \mathrm{Mn}$ is more prone than Al-22.5\%Mn alloy composition. A high amount of pure metal phases was detected in Al-20\%Cu-20-15\%Mn composite as per the EDS analysis (Table 5), and this composition is a multi-alloyed composite with numerous phases and intermetallic. 


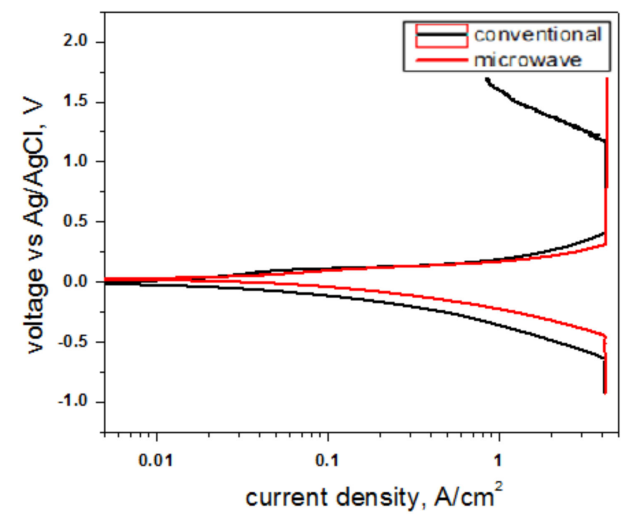

(a)

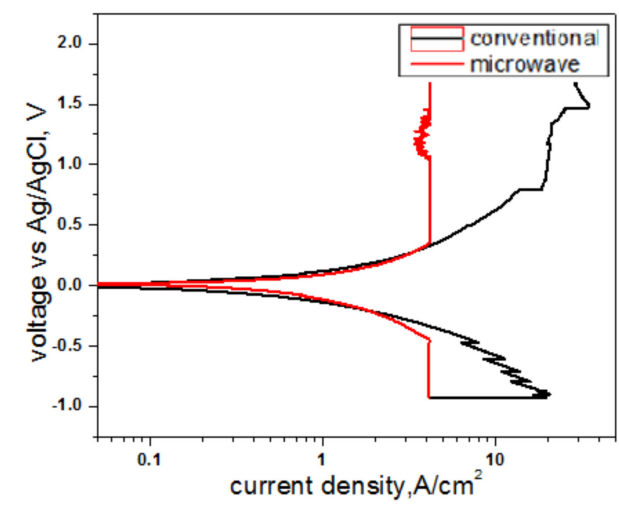

(b)

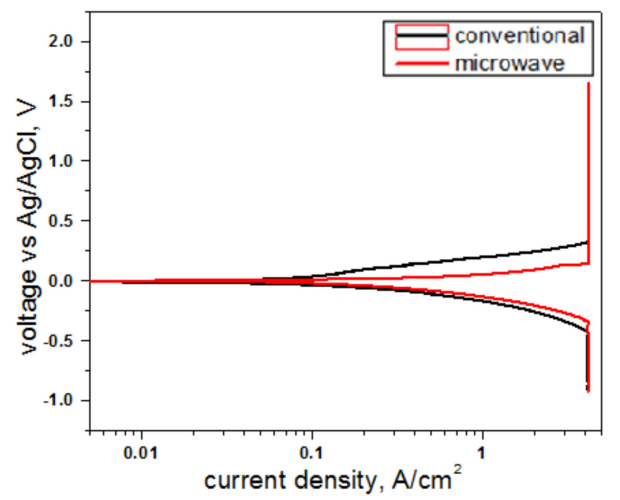

(c)

Figure 4. Comparison of the potentiodynamic polarization curves of conventionally and Microwave sintered (a) Al-22.5\%Mn, (b) Al-18.6\%Cu-24.12\%Mn, and (c) Al-20\%Cu-15\%Mn composites.

\section{Conclusions}

Using microwave sintering and conventional sintering, three alloys (77.5Al-22.5Mn, 57.28Al-18.6Cu-24.12Mn, and 65Al-20Cu-15Mn) were sintered at $550{ }^{\circ} \mathrm{C}$ for $60 \mathrm{~min}$. After sintering, they were aged at $150{ }^{\circ} \mathrm{C}$, and corrosion tests were also under taken with the aged alloys. The following conclusion was made from this study.

Microwave sintered compacts exhibited higher densification factors and hardness when compared to conventional sintering. Microwave sintered alloys have finer microstructures and narrower pore sizes than conventional alloys, as evidenced by SEM microstructures. The results of EDS proved that the alloy formation of Mn with Al was more likely and was more prominent in the case of microwave sintering. Al-20\%Cu-15\%Mn showed less hardness and smaller grain size in the microwave sintering than $\mathrm{Al}-18.6 \% \mathrm{Cu}-24.12 \% \mathrm{Mn}$. Higher corrosion resistance was observed in the case of microwave sintering due to the uniform dissolution of elements. Microwave sintering can be considered the best alternative to the conventional sintering technique for $\mathrm{Al}$ alloys processed via powder metallurgy.

Author Contributions: Conceptualization, A.M. and A.R.A.; methodology, A.R.A.; formal analysis, A.M. and A.R.A.; investigation, A.M.; resources, M.S., A.R.A. and D.K.A.; data curation, A.M. and A.R.A.; writing-original draft preparation, A.M. and A.R.A.; writing-review and editing, M.S., A.R.A., D.K.A.; visualization, A.R.A. \& D.K.A.; supervision, A.R.A.; project administration, D.K.A.; funding acquisition, D.K.A. All authors have read and agreed to the published version of the manuscript.

Funding: This research received no external funding.

Institutional Review Board Statement: Not Applicable.

Informed Consent Statement: Not Applicable. 
Data Availability Statement: Data available on request due to restrictions. The data presented in this study are available on request from the corresponding author.

Acknowledgments: The authors thank VIT University for providing 'VIT SEED GRANT' for carrying out this research work.

Conflicts of Interest: The authors declare no conflict of interest.

\section{References}

1. Cobden, R.; Banbury, A. Aluminum: Physical Properties, Characteristics, and Alloys. Talat Lect. 1994, 1501, $144-155$.

2. Zheng, R.R.; Wu, Y.; Liao, S.L.; Wang, W.Y.; Wang, W.B.; Wang, A.H. Microstructure and mechanical properties of Al/(Ti,W)C composites prepared by microwave sintering. J. Alloys Compd. 2014, 590, 168-175. [CrossRef]

3. Lall, C.; Heath, W. P/M aluminium structural parts -manufacturing and metallurgical fundamentals. Int. J. Powder Met. 2000, $36,45-50$.

4. Kumar, M.G.A.; Seetharamua, S.; Nayak, J.; Satapathy, L.N. A Studyon Thermal Behavior of Aluminum Cenosphere Powder Metallurgy Composites Sinteredin Microwave. Procedia Mater. Sci. 2014, 5, 1066-1074. [CrossRef]

5. Surappa, M.K. Aluminummatrixcomposites: Challengesandopportunities. Sadhana 2003, 28, 319-334. [CrossRef]

6. Sever, S.; Liviu, R. Introduction to Powder Metallurgy. In Proceedings of the "ConstantinBrâncusi” University, 8th International Conference, Targu Jiu, Romania, 24 May 2002.

7. Groover, M.P. Fundamentals of Modern Manufacturing; John Wiley \& Sons, Inc.: Hoboken, NJ, USA, 2002.

8. Mascarenhas, J.; Marcelo, T.; Inverno, A.; Castanho, J.; Vieira, T. Microwave Sintering of Sputter Coated 3161 Powders. In Proceedings of the Euro PM2008 International Powder Metallurgy Congress \& Exhibition, Mannheim, Germany, 29 September-1 October 2008; pp. 21-26.

9. Oghbaei, M.; Mirzaee, O. Microwave versus conventional sintering: A review of fundamentals, advantages, and applications. J. Alloys Compd. 2010, 494, 175-189. [CrossRef]

10. Mahmoud, M.M.; Link, G.; Thumm, M. The role of the native oxide shellon the microwaves intering of copper metal powder compacts. J. Alloys Compd. 2015, 627, 231-237. [CrossRef]

11. Muthuchamy, A.; Annamalai, A.R.; Acharyya, S.G.; Nagaraju, N.; Agrawal, D.K. Microstructural and Electrochemical behaviour of Aluminium Alloy Composites Produced Using Different Sintering Techniques. Mat. Res. 2018, 21. [CrossRef]

12. Chen, B.; Wang, R.; Peng, C.; Feng, Y.; Wang, N. Influence of Al_Mn master alloys on microstructures an delect rochemical properties of Mg_Al_Pb_Mn alloys. Trans. Nonferrous Met. Soc. China 2014, 24, 423-430. [CrossRef]

13. Khvan, A.V.; Cheverikin, V.V.; Dinsdale, A.T.; Watson, A.; Levchenko, V.V.; Zolotorevskiy, V.S. Formation of metastable phases during solidification of Al-3.2wt\%Mn. J. Alloys Compd. 2015, 622, 223-228. [CrossRef]

14. Udomphol, T. Aluminum and Its Alloys; Suranaree University of Technology: Nakhon Ratchasima, Thailand, 2007.

15. Wolla, D.W.; Davidson, M.J.; Khanra, A.K. Studies on the formability of powder metallurgical aluminum-copper composite. Mater. Des. 2014, 59, 151-159. [CrossRef]

16. Wang, Y.; Rainforth, W.M.; Jones, H.; Lieblich, M. Dry wear behavior and its relationto microstructure of novel 6092 Aluminum alloy-Ni3 Al powder metallurgy composite. Wear 2001, 251, 1421-1432. [CrossRef]

17. Voort, V.; George, F. Metallography, Principles and Practice; ASM International: Almere, The Netherlands, 1999; p. 197, ISBN 978-0-87170-672-0.

18. Liu, G.; Zhang, G.J.; Wang, R.H.; Hu, W.; Sun, J.; Chen, K.H. Heat treatment-modulated coupling effect of multi-scale second-phase particles on the ductile fracture of aged aluminum alloys. Acta Mater. 2007, 55, 273-284. [CrossRef]

19. Padmavathi, C.; Upadhyaya, A.; Agrawal, D. Effect of Microwave and conventional heating on sintering behavior and properties of Al-Mg-Si-Cu alloy. Mater. Chem. Phys. 2011, 130, 449-457. [CrossRef]

20. Ghazali, M.J.; Rainforth, W.M.; Jones, H. Dry sliding wear behavior of some wrought, rapidly solidified powder metallurgy Aluminum alloys. Wear 2005, 259, 490-500. [CrossRef]

21. Kloc, L.; Cerri, E.; Spigarelli, S.; Evangelista, E.; Terence, G.; Langdon, B. Significance of continuous precipitation during creep of a powder metallurgy aluminum alloy. Mater. Sci. Eng. A 1996, 216, 161-168. [CrossRef]

22. Ellner, M. Crystal chemical parameters of the liquid-quenched $\mathrm{MnAl}_{0.8}$. J. Alloys Compd. 2006, 422, 192-193. [CrossRef]

23. George, F. Chromium-Free Conversion Coating of Aluminum-Copper Alloys. Ph.D. Thesis, The University of Manchester, Manchester, UK, 2010.

24. Namahoot, J. Effect of Deformation on Corrosion of Al-Mn Alloys. Ph.D. Thesis, The University of Birmingham, Birmingham, UK, 2004. 